\title{
Global COVID-19 transmission rate is influenced by precipitation seasonality and the speed of climate temperature warming
}

\author{
Katsumi Chiyomaru ${ }^{1}$ and Kazuhiro Takemoto ${ }^{\mathbf{1}^{*}}$ \\ 1) Department of Bioscience and Bioinformatics, Kyushu Institute of Technology, Iizuka, \\ Fukuoka 820-8502, Japan \\ *Corresponding author's e-mail: takemoto@bio.kyutech.ac.jp \\ Abstract
}

The novel coronavirus disease 2019 (COVID-19) became a rapidly spreading worldwide epidemic; thus, it is a global priority to reduce the speed of the epidemic spreading. Several studies predicted that high temperature and humidity could reduce COVID-19 transmission. However, exceptions exist to this observation, further thorough examinations are thus needed for their confirmation. In this study, therefore, we used a global dataset of COVID-19 cases and global climate databases and comprehensively investigated how climate parameters could contribute to the growth rate of COVID-19 cases while statistically controlling for potential confounding effects using spatial analysis. We also confirmed that the growth rate decreased with the temperature; however, the growth rate was affected by precipitation seasonality and warming velocity rather than temperature. In particular, a lower growth rate was observed for a higher precipitation seasonality and lower warming velocity. These effects were independent of population density, human life quality, and travel restrictions. The results indicate that the temperature effect is less important compared to these intrinsic climate characteristics, which might thus be useful for explaining the exceptions. However, the contributions of the climate parameters to the growth rate were moderate; rather, the contribution of travel restrictions in each country was more significant. Although our findings are preliminary owing to data-analysis limitations, they may be helpful when predicting COVID-19 transmission. 
medRxiv preprint doi: https://doi.org/10.1101/2020.04.10.20060459; this version posted April 14, 2020. The copyright holder for this preprint (which was not certified by peer review) is the author/funder, who has granted medRxiv a license to display the preprint in perpetuity.

It is made available under a CC-BY-NC-ND 4.0 International license.

\section{Introduction}

31 The world-wide spreading of coronavirus disease 2019 (COVID-19) [1], an infectious disease caused by the novel coronavirus, severe acute respiratory syndrome coronavirus 2 (SARS-CoV-2 / 2019-nCoV) was firstly identified in Wuhan, China [2]. The COVID-19 epidemic has a serious impact on the public health and economy [3], the reduction of its spreading is thus a significant challenge. How climate parameters are associated with the spreading is intriguing concerning the coronavirus characterization and spreading prediction. Previous studies have suggested that temperature increase could reduce COVID-19 transmission both in China [4-6] and at the global scale [7-11]. However, a bell-shaped or quadratic relationship between the COVID-19 transmission rate and the temperature was observed, indicating that the optimal transmission temperature could be at $\sim 8{ }^{\circ} \mathrm{C}$. Moreover, part of the previous studies [4-6, 8] also reported that higher humidity is also associated with a lower transmission rate of COVID-19. These results are consistent with the influenza seasonality (i.e., the fact that influenza transmission is reduced due to temperature and humidity increase) [12]. Thus, previous studies have predicted that the arrival of summer and the rainy season would reduce COVID-19 transmission.

However, more careful examinations are required to conclude such COVID-19 seasonality. As emphasized in part of the previous studies, temperature could account for a relatively modest amount of the total variation in the COVID-19 transmission rate [10]. In fact, despite the expectations, the spreading of COVID-19 has also been observed in warm and humid areas (e.g., Australia, Brazil, and Argentina, on Southern Hemisphere, in early March). This indicates that other climate parameters might also affect COVID-19 transmission. For example, influenza transmission is also influenced by several environmental parameters, such as ultraviolet (UV) radiation, wind speed, precipitation, and air pollution. [13]; moreover, it also correlated with diurnal temperature ranges [14] and urbanization (human impacts) [15]. In addition to this, changing rapid weather variability (e.g., climate seasonality and climate change) increases the risk of an influenza epidemic [16]. In general, seasonal variations in temperature, rainfall, and resource availability can exert strong pressure on infectious disease population dynamics [17]. Inspired by these results, previous studies evaluated the contributions of wind speed [8], precipitation and UV irradiation to COVID-19 transmission [9]. However, the remaining parameters have still been poorly investigated to date. In particular, the temperature might be associated with other climate parameters, it is thus necessary to control the potentially confounding effects [18-20].

To study the aforementioned subject, the application of spatial analysis might also be needed. Although spatial autocorrelations between observation areas and variables need to be evaluated when analyzing geographic data [18, 20,21], previous studies have 68 understudied them. It remains possible that the observed associations of COVID-19 69 transmission with temperature and humidity are spatial autocorrelation artefacts. In this study, we thus aimed at conducting a more comprehensive investigation. Using global time-series data on confirmed COVID-19 cases[1] and global climate databases, we comprehensively investigated how climate parameters contribute to COVID-19 transmission on a global scale while statistically controlling for potential confounding 
effects using spatial analysis. Population density and quality of human life (human development index) were also considered when controlling for potential confounding effects because they might affect infectious disease transmission [15], including COVID19 transmission [4]. Similarly, we also considered the travel restrictions because the national emergency response, including travel bans, appears to have delayed the growth and limited the size of the COVID-19 epidemic in China [22, 23].

\section{Material and methods}

\subsection{The growth rate of COVID-19 cases}

We obtained global time-series data for the period between January 22, 2020 - April 6, 2020, on the number of confirmed cases of COVID-19 [1] operated by the Johns Hopkins University Center for Systems Science and Engineering from their GitHub repository. In this repository, the global dataset and dataset of the (USA) were available. We combined these datasets after removing USA-related data from the global dataset. To estimate the COVID-19 transmission rate, many previous studies considered the measures based on the number of cases. However, it remains possible that the differences in the number of tested individuals between areas (countries) affect these measures. We thus used instead the growth rate of confirmed COVID-19 cases as a more suitable measure. The growth rate in each observation was computed using the $\mathrm{R}$ statistical software (version 3.6.2; www.r-project.org) and the package incidence(version 1.7.1) [24]; in particular, the fit function was used. To estimate the growth rate during the initial (exponential) phase, we used the data within 15 days ( $\sim 2$ weeks) starting from the date (call first date hereafter) when 30 and more cases were confirmed in cumulative counts, as described previously [7]. We confirmed that similar conclusions were obtained at the different cut-off values (using the data within 30 days starting from the date when 50 and more cases were confirmed).

\subsection{Climate parameters}

We obtained climate parameters from several databases based on the observation area latitudes and longitudes available in the dataset [1]. The data extraction and calculation of climate parameters were generally based on the procedures established in our previous publications [18, 20], which could be also accessed in our GitHub repository [25].

Climatic parameters with a spatial resolution of 2.5' were obtained from the WorldClim database (version 2.1) [26] for each observation area. In particular, we extracted the following monthly climate data according to the month of the median date in the data used for computing the growth rate: monthly mean temperature $\left(T_{\text {mean }} ;{ }^{\circ} \mathrm{C}\right)$, minimum temperature $\left(T_{\min } ;{ }^{\circ} \mathrm{C}\right)$, maximum temperature $\left(T_{\max } ;{ }^{\circ} \mathrm{C}\right)$, precipitation $(\mathrm{mm})$, wind speed $\left[\mathrm{ms}^{-1}\right]$, solar radiation $\left(\mathrm{UV} ; \mathrm{kJ} \mathrm{m}^{-2} \mathrm{day}^{-1}\right)$, and water vapor pressure $[\mathrm{kPa}]$. Moreover, we computed monthly diurnal temperature range (i.e., $T_{\max }-T_{\min }$; DTR; ${ }^{\circ} \mathrm{C}$ ) and relative humidity based on $T_{\text {mean }}$ and water vapor pressure. We also obtained the following annual climate parameters: temperature seasonality ( $T_{\text {seasonality }}$; standard deviation) and precipitation seasonality ( $P_{\text {seasonality; }}$ coefficient of variation). 
medRxiv preprint doi: https://doi.org/10.1101/2020.04.10.20060459; this version posted April 14, 2020. The copyright holder for this preprint (which was not certified by peer review) is the author/funder, who has granted medRxiv a license to display the preprint in perpetuity.

$115[27,28]$, defined as the temporal annual mean temperature (AMT) gradient divided by

116 the spatial AMT gradient, where the temporal gradient is defined as the difference

117 between the current and past AMT, available in the WorldClim database, and the spatial

118 gradient was the local slope of the current climate surface at the observation area,

119 calculated using the function terrain (with the option neighbors $=4$ ) in the R package

120 raster (version 2.9.5).

\section{2.4. Other related parameters}

122 To investigate the effect of population density, we obtained 2020 population density (PD)

123 data with a spatial resolution of 2.5' from the Gridded Population of the World (version

124 4) [29].

125 To evaluate human impact, we used the human footprint (HF) scores, obtained from the

126 Last of the Wild Project (version 3) [30]. The HF scores have a spatial resolution of $1 \mathrm{~km}$

127 grid cells and are defined based on human population density, human land use and

128 infrastructure, and human access.

129 To evaluate the quality of human life, we used the gross domestic product (GDP) per

130 capita and human development index (HDI), obtained from the Gridded global datasets

131 for Gross Domestic Product and Human Development Index over 1990-2015 [31]. HDI is

132 defined based on life expectancy, education, and income (GDP per capita).

133 To evaluate the effect of travel restrictions, we manually extracted the dates when travel

134 restrictions were imposed in each country from the Wikipedia page "Travel restrictions

135 related to the 2019-20 coronavirus pandemic"'[32]. The travel restrictions were classified

136 into three categories: countries and territories implementing a global travel ban (Ban),

137 countries implementing global quarantine measures (Qua), and non-global restrictions

138 (NonG). When a country imposed multiple restriction types, the date when the strongest

139 restriction was imposed was selected, where the order of the strength of travel restrictions

140 was considered as follows: Ban $>$ Qua $>$ NonG. Many countries imposed travel

141 restrictions after March 17, 2020 (see Figure S1 in our GitHub repository [25]). Thus, we

142 considered a categorical variable (Ban) for the global travel restriction trend: 0 if the first

143 date (see Section 2.1) is before March 17, 2020, and 1 otherwise.

\section{2.3. Data analyses}

145 The statistical analyses were based on the procedures in $[18,20]$. To evaluate the

146 contribution of each variable to the growth rate, regression analysis was performed using

147 R. Both ordinary least-squares (OLS) regression and the spatial analysis approach were

148 considered. The dataset and R script for data analyses, used in this study, are available in

149 our GitHub repository [25].

150 For the OLS regression, full models were constructed encompassing all explanatory

151 variables ( $T_{\text {mean }}, \mathrm{DTR}, T_{\text {seasonality, }}$ wind speed, precipitation, $P_{\text {seasonality, }} \mathrm{UV}$, humidity, PD,

152 HDI, WV, and Ban), and the best model was selected in the full model. The HF scores

153 and GDP per capita were omitted because they were strongly correlated with PD and

154 HDI, respectively. The best model was selected based on the sample-size-corrected 
version of the Akaike information criterion (AICc) values using the $\mathrm{R}$ package MuMIn (version 1.43.6). Moreover, a model-averaging approach using MuMIn was adopted. The averaged model was obtained in the top 95\% confidence set of models. A global Moran's test was performed to evaluate spatial autocorrelation in the regression residuals using the function lm.morantest.exact in the R package spdep, version 1.1.3.

160 PD and WV were log-transformed for normality. Precipitation and $P_{\text {seasonality }}$ were squareroot transformed for normality. $T_{\text {mean }}$ was rescaled with $\sqrt{\left(T_{\text {mean }}-7.8\right)^{2}}$ to the quadratic relationship between temperature and transmission rate of COVID-19 [5, 7, 8, $10,11]$. The quantitative variables were normalized to the same scale, with a mean of 0 and a standard deviation of 1 , using the scale function in $\mathrm{R}$ before the analysis.

165 For spatial analysis, a spatial eigenvector mapping (SEVM) modeling approach [21, 33] was also considered to remove spatial autocorrelation in the regression residuals. Specifically, the Moran eigenvector approach was adopted using the function SpatialFiltering in the R package spatialreg (version 1.1.5). As with the OLS regression analysis, full models were constructed, and then the best model was selected based on AICc values. The spatial filter was fixed in the model-selection procedures [33].

The contribution (i.e., non-zero estimate) of each explanatory variable to the growth rate of COVID-19 cases was considered significant when the associated $p$-value was less than

1730.05.

\section{Results and discussion}

The data in 300 areas were investigated (Figure 1). The OLS regression analysis (Table 1) and spatial analysis (Table 2) showed almost similar results because the statistical significances of spatial autocorrelations were moderate in the full model (Moran's $I=$ 0.077 , and the associated $p$-value $=0.021)$ and best model $(I=0.084, p=0.027)$ of the OLS regression analysis. The full, best, and averaged models showed almost similar results in both the OLS regression analysis and spatial analysis. The details of the results are as follows.

182 The temperature negatively correlated with the growth rate of COVID-19 cases. This 183 indicates that high temperature (e.g., the arrival of summer season) reduces COVID-19 184 transmission, consistent with several previous studies [4-11]. However, no humidity 185 contribution was observed. This discrepancy might be due to differences in the datasets 186 and data analyses between this study and previous studies. Previous studies (e.g., [4]), 187 reported the association with humidity, was limited to the data on China; moreover, they 188 used the measures based on the number of confirmed cases, although these measures may 189 be affected by the difference of COVID-19 testing between areas. The contribution of 190 humidity may be limited on a global scale. A similar tendency is observed in the case of influenza [13]; in particular, using specific humidity to determine transmission has a low predictive power at low- and mid-altitude sites, although humidity is believed to affect the transmission.

194 More importantly, however, we found that the growth rate was associated with the other parameters rather than temperature. In particular, we found that the growth rate of 
medRxiv preprint doi: https://doi.org/10.1101/2020.04.10.20060459; this version posted April 14, 2020. The copyright holder for this preprint (which was not certified by peer review) is the author/funder, who has granted medRxiv a license to display the preprint in perpetuity. It is made available under a CC-BY-NC-ND 4.0 International license .

196 COVID-19 cases showed a correlation with precipitation seasonality and warming

197 velocity. Specifically, a lower growth rate was observed during a higher precipitation

198 seasonality and a lower warming velocity; however, the contribution of precipitation

199 seasonality was higher than that of warming velocity, according to the estimates of the

200

201

202

203

204

205 models of the OLS regression analysis and spatial analysis. The observed associations may be reasonable in the context of the effects of seasonality and changing rapid weather variability on population dynamics of infectious diseases [17]. In particular, theory and experiment have indicated that climate seasonality can alter the spread and persistence of infectious diseases and that population-level responses can range from simple annual cycles to more complex multiyear variations. Therefore, climate seasonality and historical climate change can affect infectious disease transmission. In fact, rapid weather variability played a significant role in changing the strength of the influenza epidemic in the past [16]. However, the reason why temperature seasonality did not correlate with the growth rate remains unclear. Nevertheless, these results (the contribution of precipitation seasonality, in particular) may explain the exceptions (i.e., why the spreads of COVID-19 are also observed in warm areas although previous studies suggest that high temperature reduces COVID-19 transmission). This may be because of the difference in precipitation seasonality between the observation areas. For example, the areas in Australia, Brazil, and Argentina were warm in March; however, they show low precipitation seasonality

215 (Figure 2). Thus, the spreads might occur in these areas. Moreover, Europe and the USA 216 might have undergone rapid spreads because they show low precipitation seasonality; on 217 the other hand, the spread might have reached a peak relatively quickly in China because 218 of relatively high precipitation seasonality.

219 The contribution of solar radiation is currently ambiguous. Solar radiation showed a 220 positive association with the growth rate of COVID-19 cases. However, the results were less robust; in particular, the contribution was statistically significant in spatial analysis (Table 2), but not in the full and averaged models in the OLS regression (Table 1). Thus, it remains possible that the contributions partly observed in the analyses are artefacts. Assuming the positive association, the result is inconsistent with the fact that solar (UV) radiation is expected to reduce infection disease (e.g., influenza) transmission [13]. Moreover, a pairwise correlation analysis showed no association between the growth rate and solar radiation (Spearman's rank correlation coefficient $r=-0.06, p=0.31$ ).

228 The contributions of wind speed and precipitation were also limited. This is inconsistent 229 with previous studies [8, 9]; however, statistical significances were not evaluated in these 230 studies. This discrepancy might be due to differences in the data analyses between this 231 study and previous studies. In particular, previous studies used the measures based on the number of confirmed cases; however, these measures may be affected by the difference of COVID-19 testing between areas. Hence, further examinations may be needed, given the importance of these climate parameters in infectious disease transmission $[13,17]$.

235 Non-climate parameters were also associated with the growth rate of COVID-19.

236 According to the estimates of the models of the OLS regression analysis and spatial analysis, the contribution of travel restrictions was most significant than those of the climate parameters; in particular, travel restrictions showed a negative association with the growth rate. This result may be an extension of the result that the reduction of 240 COVID-19 transmission due to interventions, including travel restrictions, in China [22, 
medRxiv preprint doi: https://doi.org/10.1101/2020.04.10.20060459; this version posted April 14, 2020. The copyright holder for this preprint (which was not certified by peer review) is the author/funder, who has granted medRxiv a license to display the preprint in perpetuity.

It is made available under a CC-BY-NC-ND 4.0 International license.

$24123]$. Our result implies that the travel restrictions in each country contributed to reducing

242 COVID-19 transmission on a global scale.

243 The quality of human life (HDI) showed a positive association with the growth rate of

244 COVID-19. This may be because HDI reflects life expectancy (i.e., areas with a higher

245 HDI tend to have more older individuals because of a higher quality of human life).

246 COVID-19 has the age specificity of cases and attack rates [34]; in particular, the

247 epidemic risks of disease given exposure are likely to be the highest among adults aged

248 from 50-69 years. Thus, the growth rate is expected to increase with HDI.

\section{4. Conclusions}

250 Intrigued by the question why COVID-19 transmission is observed in warm areas

251 despites previous expectations of COVID-19 transmission reduction at high temperatures,

252 we comprehensively investigated how several climate parameters are associated with the

253 growth rate of COVID-19 cases and found that it was affected by precipitation

254 seasonality and warming velocity rather than temperature. The effects were independent

255 of population density, quality of human life, and travel restrictions. Our findings must

256 necessarily be considered preliminary due to several limitations; in particular, it remains

257 possible that the observed association is indirect. However, they may enhance our understanding of the COVID-19 transmission. As previous studies mentioned, high temperatures might reduce COVID-19 transmission. However, the effects may be restricted by intrinsic climate characteristics, such as precipitation seasonality and warming velocity. Moreover, the contributions of climate parameters to the growth rate of COVID-19 cases were moderate, while those of national emergency responses (i.e., travel restrictions) were more significant. Thus, slowing down the spread of COVID-19 due to the arrival of the summer season might not be expected. Instead, global collaborative interventions might be necessary to halt the epidemic outbreak.

\section{Ethics}

267 This study required no ethical permission.

\section{Data availability}

269 The datasets generated and analyzed in the current study are available in the GitHub

270 repository: https://github.com/kztakemoto/covid19climate. The relevant R codes can be

271 also found in the GitHub repository.

\section{Authors' contributions}

273 KT conceived and designed the study. KC and KT prepared the data and performed data analysis, interpreted the results, and wrote the manuscript. Both authors gave their final

275 approval for publication.

\section{Competing interests}

277 There are no competing interests to declare. 
medRxiv preprint doi: https://doi.org/10.1101/2020.04.10.20060459; this version posted April 14, 2020. The copyright holder for this preprint (which was not certified by peer review) is the author/funder, who has granted medRxiv a license to display the preprint in perpetuity.

\section{Funding}

279 No specific funding was awarded for this research.

\section{Acknowledgements}

281 The authors would like to thank Editage (www.editage.com) for English language

282 editing.

\section{References}

285 1. Dong E, Du H, Gardner L. An interactive web-based dashboard to track COVID-19 in

286 real time. Lancet Infect Dis. 2020. doi:10.1016/S1473-3099(20)30120-1.

287 2. Huang C, Wang Y, Li X, Ren L, Zhao J, Hu Y, et al. Clinical features of patients

288 infected with 2019 novel coronavirus in Wuhan, China. Lancet. 2020;395:497-506.

289 doi:10.1016/S0140-6736(20)30183-5.

290 3. Ahmed F, Ahmed N, Pissarides C, Stiglitz J. Why inequality could spread COVID-19.

291 Lancet Public Heal. 2020. doi:10.1016/S2468-2667(20)30085-2.

292 4. Wang J, Tang K, Feng K, Lv W. High temperature and high humidity reduce the

293 transmission of COVID-19. SSRN Electron J. 2020. doi:10.2139/ssrn.3551767.

294 5. Shi P, Dong Y, Yan H, Li X, Zhao C, Liu W, et al. The impact of temperature and

295 absolute humidity on the coronavirus disease 2019 (COVID-19) outbreak - evidence

296 from China. medRxiv. 2020;:2020.03.22.20038919. doi:10.1101/2020.03.22.20038919.

297 6. Oliveiros B, Caramelo L, Ferreira NC, Caramelo F. Role of temperature and humidity

298 in the modulation of the doubling time of COVID-19 cases. medRxiv.

299 2020;:2020.03.05.20031872. doi:10.1101/2020.03.05.20031872.

300 7. Notari A. Temperature dependence of COVID-19 transmission. 2020.

301 http://arxiv.org/abs/2003.12417.

302 8. Chen B, Liang H, Yuan X, Hu Y, Xu M, Zhao Y, et al. Roles of meteorological

303 conditions in COVID-19 transmission on a worldwide scale. medRxiv.

304 2020;:2020.03.16.20037168. doi:10.1101/2020.03.16.20037168.

305 9. Araujo MB, Naimi B. Spread of SARS-CoV-2 Coronavirus likely to be constrained by 306 climate. medRxiv. 2020;:2020.03.12.20034728. doi:10.1101/2020.03.12.20034728.

307 10. Bannister-Tyrrell M, Meyer A, Faverjon C, Cameron A. Preliminary evidence that 308 higher temperatures are associated with lower incidence of COVID-19, for cases reported 309 globally up to 29th February 2020. medRxiv. 2020;:2020.03.18.20036731.

310 doi:10.1101/2020.03.18.20036731. 
medRxiv preprint doi: https://doi.org/10.1101/2020.04.10.20060459; this version posted April 14, 2020. The copyright holder for this preprint (which was not certified by peer review) is the author/funder, who has granted medRxiv a license to display the preprint in perpetuity.

311 11. Wang M, Jiang A, Gong L, Luo L, Guo W, Li C, et al. Temperature significant

312 change COVID-19 Transmission in 429 cities. medRxiv. 2020;:2020.02.22.20025791.

313 doi:10.1101/2020.02.22.20025791.

314 12. Lipsitch M, Viboud C. Influenza seasonality: Lifting the fog. Proc Natl Acad Sci.

315 2009;106:3645-6. doi:10.1073/pnas.0900933106.

316 13. Sooryanarain H, Elankumaran S. Environmental Role in Influenza Virus Outbreaks.

317 Annu Rev Anim Biosci. 2015;3:347-73. doi:10.1146/annurev-animal-022114-111017.

318 14. Park J, Son W, Ryu Y, Choi SB, Kwon O, Ahn I. Effects of temperature, humidity,

319 and diurnal temperature range on influenza incidence in a temperate region. Influenza

320 Other Respi Viruses. 2020;14:11-8. doi:10.1111/irv.12682.

321 15. Dalziel BD, Kissler S, Gog JR, Viboud C, Bjørnstad ON, Metcalf CJE, et al.

322 Urbanization and humidity shape the intensity of influenza epidemics in U.S. cities.

323 Science. 2018;362:75-9. doi:10.1126/science.aat6030.

324 16. Liu Q, Tan Z-M, Sun J, Hou Y, Fu C, Wu Z. Changing rapid weather variability increases influenza epidemic risk in a warming climate. Environ Res Lett. 2020;15:044004. doi:10.1088/1748-9326/ab70bc.

327 17. Altizer S, Dobson A, Hosseini P, Hudson P, Pascual M, Rohani P. Seasonality and 328 the dynamics of infectious diseases. Ecol Lett. 2006;9:467-84. doi:10.1111/j.1461329 0248.2005.00879.x.

330 18. Takemoto K, Kajihara K. Human impacts and climate change influence nestedness 331 and modularity in food-web and mutualistic networks. PLoS One. 2016;11:e0157929.

332 doi:10.1371/journal.pone.0157929.

333 19. Dobashi T, Iida M, Takemoto K. Decomposing the effects of ocean environments on 334 predator-prey body-size relationships in food webs. R Soc Open Sci. 2018;5:180707.

335 doi:10.1098/rsos.180707.

336 20. Nagaishi E, Takemoto K. Network resilience of mutualistic ecosystems and 337 environmental changes: an empirical study. R Soc Open Sci. 2018;5:180706.

338 doi:10.1098/rsos.180706.

339 21. Dormann CF, McPherson JM, Araújo MB, Bivand R, Bolliger J, Carl G, et al.

340 Methods to account for spatial autocorrelation in the analysis of species distributional

341 data: a review. Ecography (Cop). 2007;30:609-28. doi:10.1111/j.2007.0906-

342 7590.05171.x.

343 22. Kraemer MUG, Yang C-H, Gutierrez B, Wu C-H, Klein B, Pigott DM, et al. The 344 effect of human mobility and control measures on the COVID-19 epidemic in China. 345 Science. 2020;:eabb4218. doi:10.1126/science.abb4218.

346 23. Tian H, Liu Y, Li Y, Wu C-H, Chen B, Kraemer MUG, et al. An investigation of 347 transmission control measures during the first 50 days of the COVID-19 epidemic in 
medRxiv preprint doi: https://doi.org/10.1101/2020.04.10.20060459; this version posted April 14, 2020. The copyright holder for this preprint (which was not certified by peer review) is the author/funder, who has granted medRxiv a license to display the preprint in perpetuity.

It is made available under a CC-BY-NC-ND 4.0 International license .

348 China. Science. 2020;:eabb6105. doi:10.1126/science.abb6105.

349 24. Kamvar ZN, Cai J, Pulliam JRC, Schumacher J, Jombart T. Epidemic curves made easy using the R package incidence. F1000Research. 2019;8:139.

351 doi:10.12688/f1000research.18002.1.

352

353

354

355

356

357

358

359

360

361

362

363

364

365

366

367

368

369

370

371

372

373

374

375

376

377

378

379

380
25. Chiyomaru K, Takemoto K. Global COVID-19 transmission rate is influenced by precipitation seasonality and the speed of climate temperature warming. GitHub Repos. https://github.com/kztakemoto/covid19climate.

26. Hijmans RJ, Cameron SE, Parra JL, Jones PG, Jarvis A. Very high resolution interpolated climate surfaces for global land areas. Int J Climatol. 2005;25:1965-78. doi:10.1002/joc.1276.

27. Sebastián-González E, Dalsgaard B, Sandel B, Guimarães PR. Macroecological trends in nestedness and modularity of seed-dispersal networks: human impact matters. Glob Ecol Biogeogr. 2015;24:293-303. doi:10.1111/geb.12270.

28. Sandel B, Arge L, Dalsgaard B, Davies RG, Gaston KJ, Sutherland WJ, et al. The influence of late Quaternary climate-change velocity on species endemism. Science. 2011;334:660-4. doi:10.1126/science.1210173.

29. University C for IESIN-C-C. Gridded Population of the World, Version 4 (GPWv4): Population Density, Revision 11. 2018. doi:10.7927/H49C6VHW.

30. Sanderson EW, Jaiteh M, Levy MA, Redford KH, Wannebo A V., Woolmer G. The human footprint and the last of the wild. Bioscience. 2002;52:891-904. doi:10.1641/0006-3568(2002)052[0891:THFATL]2.0.CO;2.

31. Kummu M, Taka M, Guillaume JHA. Gridded global datasets for Gross Domestic Product and Human Development Index over 1990-2015. Sci Data. 2018;5:180004. doi:10.1038/sdata.2018.4.

32. Travel restrictions related to the 2019-20 coronavirus pandemic. https://en.wikipedia.org/wiki/Travel_restrictions_related_to_the_201920_coronavirus_pandemic.

33. Diniz-filho JAF, Rangel TFLVB, Bini LM. Model selection and information theory in geographical ecology. Glob Ecol Biogeogr. 2008;17:479-88.

34. Mizumoto K, Omori R, Nishiura H. Age specificity of cases and attack rate of novel coronavirus disease (COVID-19). medRxiv. 2020;:2020.03.09.20033142. doi:10.1101/2020.03.09.20033142. 


\section{Tables}

Table 1. Influence of explanatory variables on the growth rate of COVID-19 cases based on the ordinary least squared regression approach. The results of the full model, best model, and averaged model are shown, respectively. The abbreviations of variables are as follows: $T_{\text {mean }}$ (monthly mean temperature), DTR (monthly diurnal temperature range), $T_{\text {seasonality }}$ (temperature seasonality), $P_{\text {seasonality }}$ (precipitation seasonality), UV (monthly solar radiation index), WV (warming velocity), PD (population density), HDI (human development index), and Ban (travel restrictions). $R^{2}$ denotes the coefficient of determination for full and best models based on the OLS regression. SE is the standard error. Values in brackets are the associated $p$-values.

\begin{tabular}{|c|c|c|c|c|c|c|c|c|c|}
\hline \multirow{2}{*}{ Variables } & \multicolumn{3}{|c|}{ Full model } & \multicolumn{3}{|c|}{ Best model } & \multicolumn{3}{|c|}{ Averaged model } \\
\hline & Estimate & SE & $p$-value & Estimate & SE & $p$-value & Estimate & $\mathrm{SE}$ & $p$-value \\
\hline$T_{\text {mean }}$ & -0.18 & 0.07 & 0.014 & -0.17 & 0.06 & $9.0 \times 10^{-3}$ & -0.16 & 0.07 & 0.032 \\
\hline Humidity & -0.10 & 0.09 & 0.27 & & & & -0.12 & 0.08 & 0.14 \\
\hline DTR & 0.02 & 0.09 & 0.86 & & & & 0.08 & 0.09 & 0.36 \\
\hline$T_{\text {seasonality }}$ & -0.14 & 0.09 & 0.14 & & & & -0.13 & 0.09 & 0.15 \\
\hline Wind speed & -0.05 & 0.07 & 0.53 & & & & -0.04 & 0.07 & 0.57 \\
\hline Precipitation & -0.03 & 0.08 & 0.73 & & & & -0.01 & 0.08 & 0.90 \\
\hline$P_{\text {seasonality }}$ & -0.30 & 0.10 & $1.3 \times 10^{-4}$ & -0.28 & 0.07 & $7.2 \times 10^{-5}$ & -0.30 & 0.08 & $9.2 \times 10^{-5}$ \\
\hline UV & 0.13 & 0.03 & 0.18 & 0.23 & 0.07 & $5.4 \times 10^{-4}$ & 0.18 & 0.09 & 0.060 \\
\hline WV & 0.18 & 0.07 & $9.1 \times 10^{-3}$ & 0.14 & 0.06 & 0.017 & 0.15 & 0.07 & 0.028 \\
\hline PD & -0.06 & 0.06 & 0.27 & & & & -0.06 & 0.06 & 0.35 \\
\hline HDI & 0.24 & 0.08 & $9.1 \times 10^{-3}$ & 0.21 & 0.07 & $1.8 \times 10^{-3}$ & 0.23 & 0.08 & $1.7 \times 10^{-3}$ \\
\hline Ban & -0.68 & 0.13 & $3.2 \times 10^{-7}$ & -0.71 & 0.12 & $1.8 \times 10^{-8}$ & -0.68 & 0.13 & $1.0 \times 10^{-7}$ \\
\hline $\begin{array}{l}\text { Moran's I } \\
R^{2} \\
\text { AICc }\end{array}$ & \multicolumn{3}{|c|}{$\begin{array}{c}0.077(0.021) \\
0.26\left(2.1 \times 10^{-13}\right) \\
791\end{array}$} & \multicolumn{3}{|c|}{$\begin{array}{c}0.084(0.027) \\
0.24\left(1.2 \times 10^{-15}\right) \\
783\end{array}$} & & & \\
\hline
\end{tabular}


Table 2. Influence of explanatory variables on the growth rate of COVID-19 cases based on the spatial analysis approach. The results of the full model, best model, and averaged model are shown. $R^{2}$ denotes the coefficient of determination for full and best models based on the SEVM modelling. SE is the standard error. Values in brackets are the associated $p$-values. See Table 1 for description of table elements.

\begin{tabular}{|c|c|c|c|c|c|c|c|c|c|}
\hline \multirow{2}{*}{ Variables } & \multicolumn{3}{|c|}{ Full model } & \multicolumn{3}{|c|}{ Best model } & \multicolumn{3}{|c|}{ Averaged model } \\
\hline & Estimate & $\mathrm{SE}$ & $p$-value & Estimate & SE & $p$-value & Estimate & SE & $p$-value \\
\hline$T_{\text {mean }}$ & -0.20 & 0.07 & $4.8 \times 10^{-3}$ & -0.21 & 0.06 & $1.4 \times 10^{-3}$ & -0.20 & 0.07 & $3.1 \times 10^{-3}$ \\
\hline Humidity & -0.03 & 0.09 & 0.73 & & & & -0.05 & 0.08 & 0.55 \\
\hline DTR & 0.07 & 0.09 & 0.47 & & & & 0.09 & 0.07 & 0.21 \\
\hline$T_{\text {seasonality }}$ & -0.01 & 0.09 & 0.89 & & & & 0.00 & 0.09 & 0.99 \\
\hline Wind speed & -0.03 & 0.07 & 0.68 & & & & -0.04 & 0.07 & 0.59 \\
\hline Precipitation & 0.02 & 0.08 & 0.77 & & & & 0.01 & 0.08 & 0.87 \\
\hline$P_{\text {seasonality }}$ & -0.32 & 0.08 & $1.2 \times 10^{-4}$ & -0.31 & 0.07 & $1.5 \times 10^{-5}$ & -0.33 & 0.08 & $2.1 \times 10^{-5}$ \\
\hline UV & 0.24 & 0.10 & 0.013 & 0.30 & 0.07 & $2.1 \times 10^{-5}$ & 0.27 & 0.08 & $1.0 \times 10^{-3}$ \\
\hline WV & 0.19 & 0.07 & $3.7 \times 10^{-3}$ & 0.20 & 0.06 & $8.7 \times 10^{-4}$ & 0.19 & 0.06 & $2.8 \times 10^{-3}$ \\
\hline PD & -0.03 & 0.06 & 0.55 & & & & -0.04 & 0.06 & 0.49 \\
\hline HDI & 0.21 & 0.08 & $9.3 \times 10^{-3}$ & 0.21 & 0.07 & $2.1 \times 10^{-3}$ & 0.21 & 0.07 & $3.1 \times 10^{-3}$ \\
\hline Ban & -0.73 & 0.13 & $2.5 \times 10^{-8}$ & -0.72 & 0.12 & $4.8 \times 10^{-9}$ & -0.73 & 0.12 & $<2.0 \times 10^{-16}$ \\
\hline $\begin{array}{l}\text { Moran's } I \\
R^{2} \\
\text { AICc } \\
\end{array}$ & \multicolumn{3}{|c|}{$\begin{array}{c}-0.052(0.51) \\
0.33\left(2.9 \times 10^{-16}\right) \\
773\end{array}$} & \multicolumn{3}{|c|}{$\begin{array}{c}-0.054(0.60) \\
0.32\left(<2.2 \times 10^{-16}\right) \\
763\end{array}$} & & & \\
\hline
\end{tabular}


medRxiv preprint doi: $h t t p s: / / d o i . o r g / 10.1101 / 2020.04 .10 .20060459$; this version posted April 14, 2020. The copyright holder for this preprint (which was not certified by peer review) is the author/funder, who has granted medRxiv a license to display the preprint in perpetuity. It is made available under a CC-BY-NC-ND 4.0 International license .

\section{Figures}

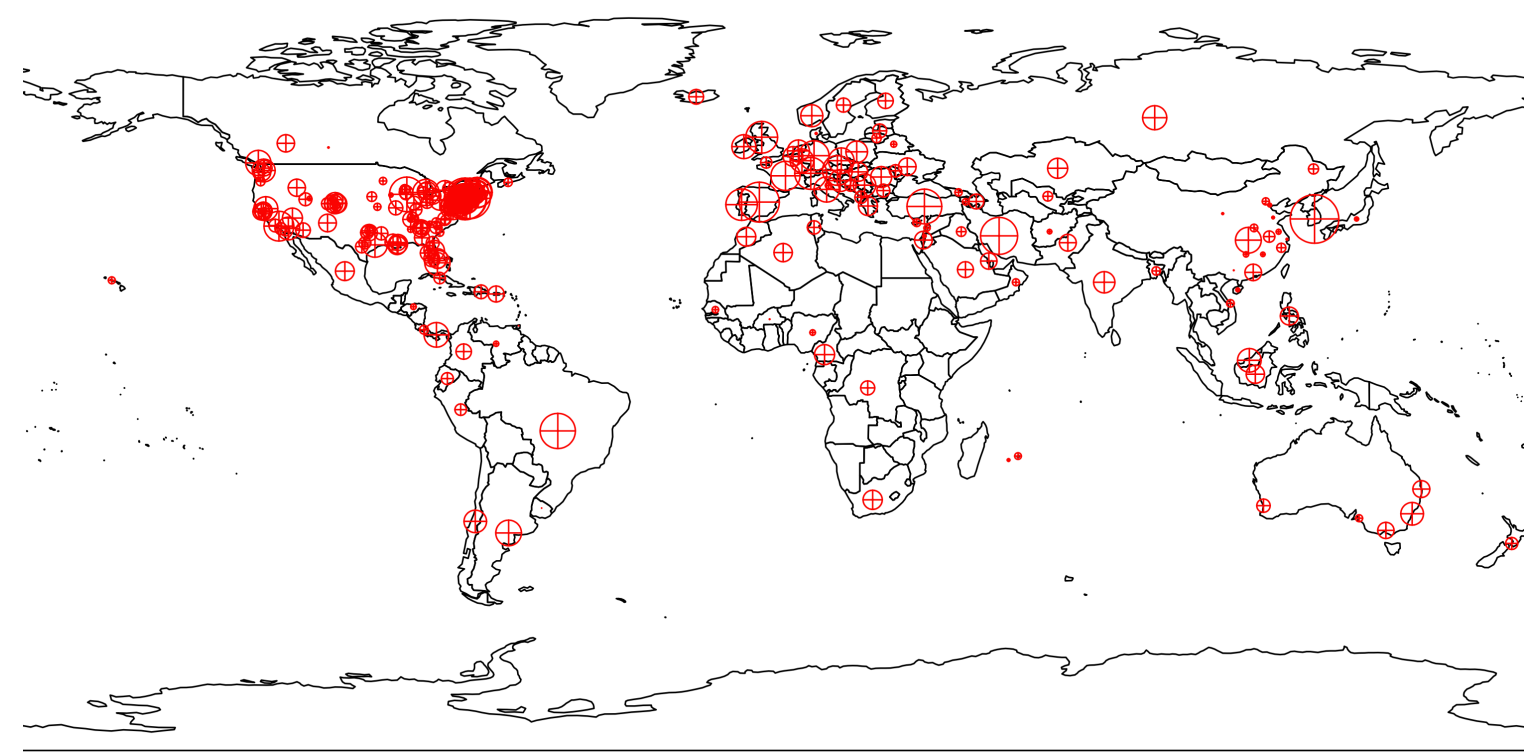

Figure 1. Distribution of the observation areas included in this study. Red symbols indicate the observation areas. Symbol size indicates the growth rate of COVID-19 cases.

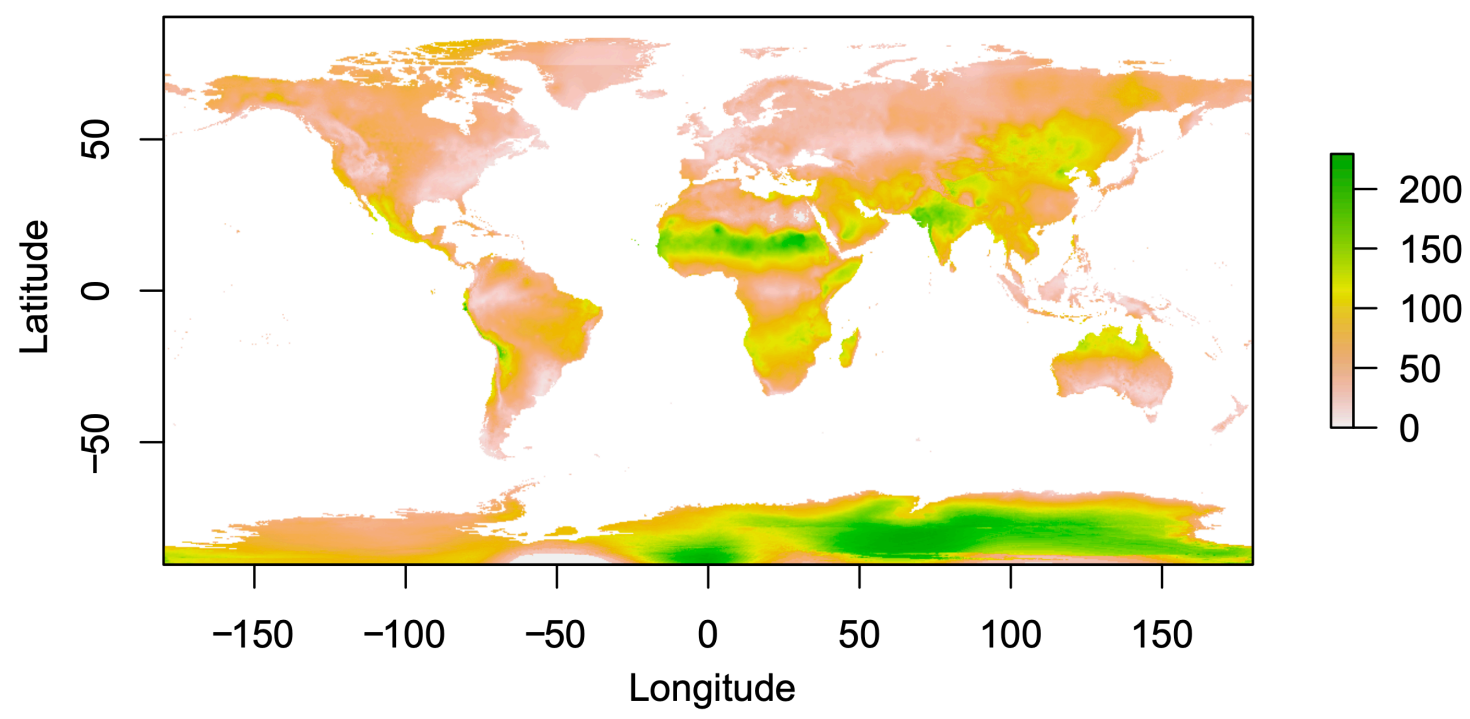

Figure 2. World distribution of precipitation seasonality. 